\title{
Autologous emulsified fat injection for rejuvenation of scars: A prospective observational study
}

\author{
Lekshmi S. Bhooshan, M. Geetha Devi'ㄹ, R. Aniraj², P. Binod, M. Lekshmi \\ Departments of Plastic Surgery and ${ }^{1}$ Department Of Community Medicine, Government Medical College, Kottayam, \\ ${ }^{2}$ Department of Plastic Surgery, Government Medical College, Trivandrum, Kerala, India
}

Address for correspondence: Dr. Lekshmi S. Bhooshan, A9 Quarters, Government Medical College, Gandhinagar (PO), Kottayam - 686 008, Kerala, India. E-mail: lekshmibhooshan@gmail.com

\section{ABSTRACT}

Background: The skin rejuvenation potential of the autologous emulsified nanofat was studied by Tonnard et al. in 2013. This property is due to the viable adipose-derived stem cells present in the nanofat; although, there are no viable adipocytes. The aim of this study was to determine the aesthetic outcome of autologous emulsified nanofat injection in scars using a standardised and validated Patient Observer Scar Assessment Scale (POSAS) and photographs. Materials and Methods: A total of 34 patients with scars of varied aetiologies were included in the study as per inclusion criteria. Pre-operative scoring of the scars with the POSAS scale was done, and photographs were taken. Fat aspiration was done from the lower abdominal wall using syringe liposuction under tumescent anaesthesia. The lipoaspirate was mechanically emulsified, filtered and injected intralesionally into the scar using 26G needle and insulin syringe. Post-operative scar reassessment was done at 3 months with the POSAS scale score and photographs. The improvement in scar characteristics and symptoms were tested statistically using a paired $t$-test. Pre-operative and post-operative photographic comparison was also done. Results: Out of the 34 patients included in the study, male:female ratio was $22: 12$. Majority $(79.4 \%)$ had post-traumatic facial scars. On statistical analysis, there was statistically significant improvement in symptoms such as pain $(P=0.001)$, itching $(P=0.001)$, stiffness $(P=0.001)$, thickness $(P=0.001)$, colour $(P=0.001)$, irregularity $(P=0.001)$ and scar characteristics such as vascularity $(P=0.005)$, relief $(P=0.001)$, pliability $(P=0.001)$, thickness $(P=0.001)$ and pigmentation $(P=0.001) 3$ months after injection. The photographic comparison also showed good aesthetic outcome. Conclusion: Autologous emulsified nanofat injection is effective in improving the scar characteristics as well as symptoms and helps in scar rejuvenation.

\section{KEYWORDS}

Adipose-derived stem cells; autologous emulsified fat; nanofat; rejuvenation; scars

\begin{tabular}{|l|l|}
\hline \multicolumn{2}{|c|}{ Access this article online } \\
\hline Quick Response Code: & Website: \\
\hline & www.ijps.org \\
\cline { 2 - 2 } & Dol: \\
\hline & 10.4103/ijps.IJPS_86_17 \\
\hline
\end{tabular}

This is an open access journal, and articles are distributed under the terms of the Creative Commons Attribution-NonCommercial-ShareAlike 4.0 License, which allows others to remix, tweak, and build upon the work non-commercially, as long as appropriate credit is given and the new creations are licensed under the identical terms.

For reprints contact: reprints@medknow.com

How to cite this article: Bhooshan LS, Devi MG, Aniraj R, Binod P, Lekshmi M. Autologous emulsified fat injection for rejuvenation of scars: A prospective observational study. Indian J Plast Surg 2018;51:77-83. 


\section{INTRODUCTION}

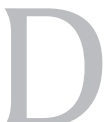

isfiguring scars in the exposed parts of the body creates psychological trauma and social embarrassment to the sufferer. Scar revision is a challenge to any practicing cosmetic surgeon. Rejuvenation of existing scar without revision surgery reduces the psychological stress of the patient as well as the doctor. Autologous fat had been used as filler in various augmentation and contour correction procedures utilising the lipofilling property of adipocytes. ${ }^{[1-4]}$ In 2001, Zuk et al. introduced multipotent progenitor cells called adipose-derived stem cells (ADSCs), which are present as stromal vascular fraction and CD34+ subfraction. ${ }^{[5,6]}$ The study of Tonnard et al. ${ }^{[1]}$ in 2013 had proven that mechanically emulsified autologous fat also called as nanofat retains the regenerative potential because it is rich in ADSC; although, it lacks lipofilling property due to the absence of viable adipocytes. His study had shown remarkable effects in skin rejuvenation after nanofat injection..$^{[1]}$ Clinical study of the use of nanofat in scar rejuvenation and its objective assessment for improvement using standard validated tool has not been reported in the literature.

The objective of this study was to evaluate the effectiveness of the emulsified autologous fat or nanofat in the rejuvenation of scar by assessing the aesthetic outcome regarding patient symptoms such as pain, itching, color, stiffness and scar characteristics such as vascularity, pigmentation, pliability and thickness of the scar using the Patient Observer Scar Assessment Scale (POSAS) and clinical photographs.

\section{MATERIALS AND METHODS}

We conducted a prospective observational study during a period of 1 year from July 2015 to July 2016 in a tertiary care centre. The study design adopted was a prospective observational research design. Thirty-four patients attending the plastic surgery outpatient department with scars demanding scar revision were included in the study. Patients with unstable scars, malignancies and contractures were excluded from the study. Ethical committee clearance was obtained from the Institutional Review Board. Informed written consent was obtained from all the patients.Pre-operative POSAS observer scale ${ }^{[2]}$ scoring was done by the principal investigator and the patient scale scoring was done by patient under investigator's supervision. Photographic documentation was also done for all cases.

The POSAS is a comprehensive scale that was designed for the evaluation of all types of scars, and it has the advantage that it evaluates the scar in the patient and observers perspective. ${ }^{[3]}$ The patient scale gives the POSAS an important extra dimension because the patient's opinion is mandatory for a complete scar assessment. The internal consistency; of both the patient and observer scale; as shown by Cronbach's alpha was 0.86 and 0.90 , respectively. ${ }^{[3]}$ The observer scale was scored by the principal investigator herself in all the cases.

The observer scale of POSAS has six scar parameters - vascularity, pigmentation, thickness, relief, pliability and surface area. Each parameter was scored from 1 to 10 . Score 1 was given when the scar matches that of normal skin. Score 10 was given for the worst scar imaginable. The total minimum score on observer scale was 6 , and the maximum score was 60 .

The patient scale on POSAS also has six parameters - pain, itching, colour, thickness, stiffness and irregularity and each parameter was scored from 1 to 10 . Score 1 was given if there were no symptoms and matches the normal skin and score 10 for worst symptoms. The patient scale was filled by the patient under the supervision of the principal investigator. The total minimum score of the patient scale was 6 , and the maximum score was 60 .

The aesthetic outcome was evaluated based on the total patient score and total observer score on the POSAS scale. The total score of 6-24 was categorised as a good outcome; while a score of 25-60 was taken as a bad outcome. Duration of the scar was categorised as; long duration ( $>5$ years) and short duration ( $<5$ years).

\section{Surgical technique}

The procedure was done under tumescent anaesthesia with aseptic precautions. The fat was aspirated from the lower abdominal wall in all cases using $3 \mathrm{~mm}$ mirrored triport Colemans cannula and 10cc Leur Lock syringe by syringe liposuction technique [Figure 1a]. The aspirated fat was kept undisturbed for 10-15 min in the vertical position in a $200 \mathrm{ml}$ sterile steel tumbler after capping it with hypodermic needle to avoid leakage [Figure 1b]. The tumescent fluid separating from the aspirate was discarded. The supernatant fat was emulsified to a milky white emulsion 

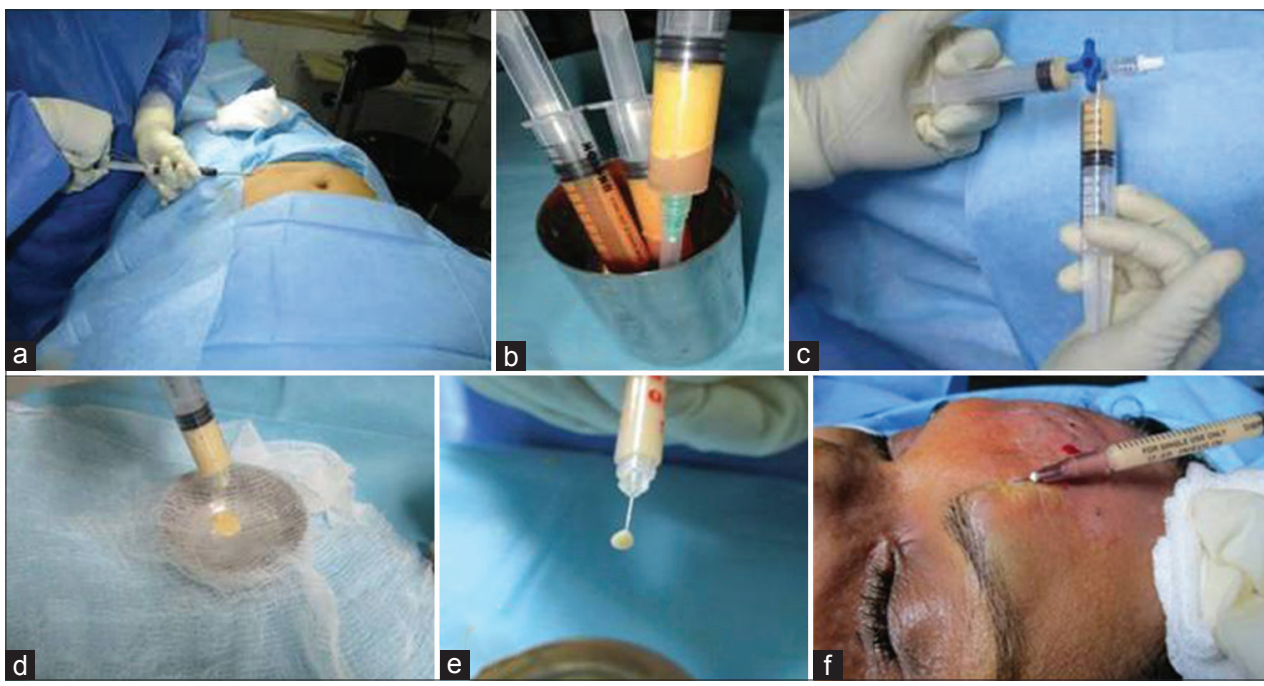

Figure 1: Technique of nanofat injection (a) syringe liposuction (b) separation of fat (c) emulsification (d) filtration with a moist saline gauze (e) emulsified fat (f) yellowish blanching marks the end point of intralesional injection

by multiple passes (30-35 passes) using two 10cc Leur Lock syringes connected with a 3-way connector [Figure 1c]. The emulsion was further sieved using a two-layered moist saline surgical gauze to remove all solid elements and to ensure free flow through a 1 inch, $27 \mathrm{G}$ needle [Figure 1d and e]. This was injected intralesionally into the scar using insulin syringe and 1inch, 27G needle. Yellowish blanching of the scar marks the end point of injection [Figure 1f]. Post-operatively, the scar was reassessed at 3 months using the POSAS Scale and photographs.

\section{Statistical analysis}

The data were collected in a prewritten proforma and were entered into a Microsoft Excel spreadsheet and analysed using Statistical Package for Social Sciences (Version 16, Chicago Inc., IL, USA). Descriptive data were shown as frequency and percentage. Association of aesthetic outcome and duration of the scar was found out using Fisher's exact test as some cells in $2 \times 2$ table was $<5$. A value of $P<0.05$ was considered as statistically significant. The Paired $t$-test was used to compare pre-operative and post-operative scar characteristics.

\section{RESULTS}

Out of the 34 patients included in the study, 22 were male and 12 were female. Mean age of the patients included was $32.2 \pm 12$ years. Twenty-seven patients $(79.4 \%)$ had post-traumatic scars, $14.7 \%(n=5)$ had post-burns and the rest post-inflammatory $(5.8 \%, n=2)$ scars [Figure 2]. The majority of the scars $(n=29,85.3 \%)$ were involving the face and the rest on the limbs $(n=5)$.

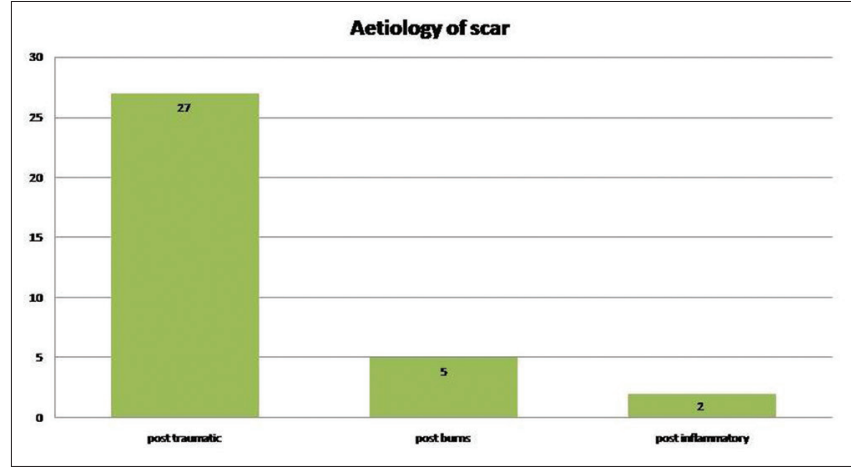

Figure 2: Bar chart showing the aetiology of scar

Twenty-eight patients $(82.4 \%)$ had hypertrophic scars, four patients (11.8\%) had flat and two patients (5.9\%) had atrophic scars [Figure 3].

Out of the 34 patients, 26 patients $(76.5 \%)$ had a good aesthetic outcome following nanofat injection while 8 patients $(23.5 \%)$ had a bad outcome [Table 1]. There was significant symptomatic improvement of the scar characteristics such as pain (paired $t=3.91, P=0.001$ ), itching (paired $t=4.64, P=0.001$ ), stiffness (paired $t=10.4, P=0.001$ ), thickness (paired $t=6.87$, $P=0.001$ ), irregularity (paired $t=5.85, P=0.001$ ) and colour (paired $t=5.98, P=0.001$ ) [Table 2]. The 3-month post-operative total patient score showed a significant improvement compared to pre-operative score (paired $t=9.71, P=0.001)[$ Table 2]

The postoperative total observer score showed a significant improvement compared to pre-operative score (paired $t=11.41, P=0.001$ ) [Table 3]. There was 
significant improvement in scar characteristics such as vascularity (paired $t=2.78, P=0.005$ ), pigmentation (paired $t=8.6, P=0.001$ ), thickness (paired $t=4.27, P=0.001$ ), pliability (paired $t=4.9, P=0.001$ ) and relief (paired $t=4.3, P=0.001$ ) [Table 3]. The surface area of scar in the observer scale of POSAS was not included for assessment except for calculation of the total score, as the total area of the scar remained unchanged after nanofat injection.

The minimum and maximum duration of scar was 3 and 204 months (17 years), respectively. Out of the 34 patients, 27 patients $(79.4 \%)$ had scars $<5$ year duration and 7 patients $(20.6 \%)$ had scars of more than 5 years duration [Table 4]. Out of the 27 patients with scars $<5$ years duration, 92.6\% $(n=25)$ had a good aesthetic outcome, whereas only $14.3 \%(n=1)$ had a good outcome in scar with $>5$ years duration. This association between shorter duration of scars and a good outcome was found statistically significant (Fischer's exact $P=0.001$ ) [Table 4].

There were eight patients with bad outcome; of which six patients had scars more than 5 years durations [Table 4]. Two patients had post-burns hypertrophic scarring with keloid tendency on the extremities of $<1$ year duration [Table 4]. They developed redness and itching and excoriation of the scar secondary to itching which required intralesional steroids for the relief of symptoms. Out of the six patients who had long duration supple scars, two of those patients underwent scar revision on demand and nanofat injection was given on the revised scars and the results were satisfactory. Four patients did not want any further intervention although there was not much improvement with nanofat injection.

\section{Representative cases Case 1}

A 38-year-old female with post-burns facial scar of 2-year duration underwent autologous emulsified fat

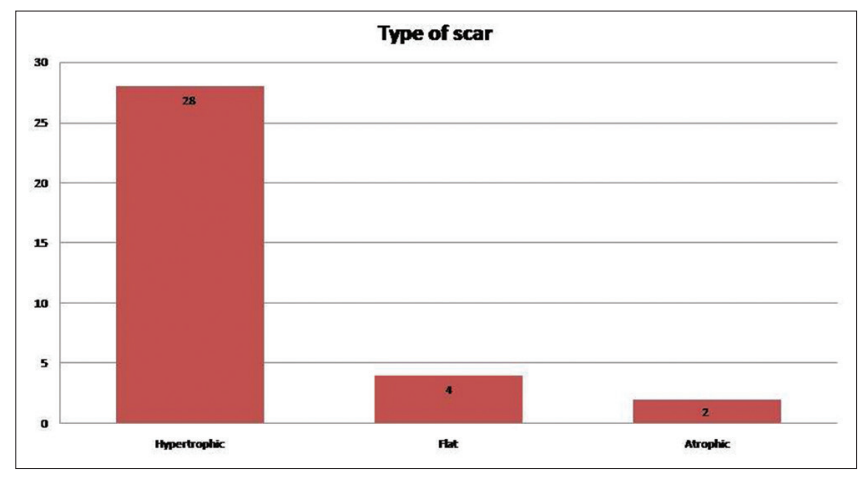

Figure 3: Bar chart showing the type of scar injection. Post-operative total POSAS score as well as photographs [Figure 4a] showed good outcome as compared to pre-operative POSAS score and photographs [Figure $4 \mathrm{~b}$ ].

\section{Case 2}

A 58-year-old female with post-traumatic scar of left cheek of 1-year duration underwent emulsified fat

Table 1: Aesthetic outcome following autologous fat injection

\begin{tabular}{lc}
\hline Outcome & $\boldsymbol{n}(\%)$ \\
\hline Good $^{* *}$ & $26(76.5)$ \\
Bad $^{*}$ & $8(23.5)$ \\
Total & $34(100)$ \\
\hline${ }^{* *}$ Outcome good if POSAS total score: $6-24$, "OOtcome bad if POSAS total \\
score: $25-60$. POSAS: Patient and Observer Scar Assessment Scale
\end{tabular}

Table 2: Comparison in the improvement of pre-operative and 3 months post-operative Patient and Observer Scar Assessment Scale score according to scar characteristics

\begin{tabular}{lcccc}
\hline \multirow{2}{*}{$\begin{array}{l}\text { Scar } \\
\text { characteristics }\end{array}$} & \multicolumn{2}{c}{ Mean (SD) } & $\boldsymbol{t}^{* *}$ & $\boldsymbol{P}^{t}$ \\
\cline { 2 - 4 } & Pre-operative & $\begin{array}{c}\text { Post-operative } \\
\text { (3 } \text { months) }\end{array}$ & \\
\hline Pain & $2.32(1.95)$ & $1.98(0.46)$ & 3.91 & 0.001 \\
Itching & $2.35(1.82)$ & $1.06(0.34)$ & 4.64 & 0.001 \\
Colour & $6.56(2.6)$ & $3.91(2.44)$ & 5.98 & 0.001 \\
Stiffness & $5.74(2.3)$ & $2.24(1.21)$ & 10.4 & 0.001 \\
Thickness & $5.5(2.4)$ & $3.0(1.86)$ & 6.87 & 0.001 \\
Irregularity & $5.6(2.2)$ & $3.12(1.6)$ & 5.85 & 0.001 \\
Total patient & $27.4(7.5)$ & $14(4.4)$ & 9.718 & 0.001 \\
score & \multicolumn{5}{l}{} \\
\hline${ }^{\dagger} P<0.05$ significant, ${ }^{* *}$ Student's $t$ value. SD: Standard deviation \\
\end{tabular}

Table 3: Comparison in the improvement of pre-operative and 3 months post-operative observer Patient and Observer Scar Assessment Scale score according to scar characteristics

\begin{tabular}{|c|c|c|c|c|}
\hline \multirow{2}{*}{$\begin{array}{l}\text { Scar } \\
\text { characteristics }\end{array}$} & \multicolumn{2}{|c|}{ Mean (SD) } & \multirow[t]{2}{*}{$t^{* *}$} & \multirow[t]{2}{*}{$\boldsymbol{P}^{\prime}$} \\
\hline & Pre-operative & $\begin{array}{c}\text { Post-operative } \\
\text { (3 months) }\end{array}$ & & \\
\hline Vascularity & $4.09(2.5)$ & $2.74(1.6)$ & 2.78 & 0.005 \\
\hline Thickness & $5.9(2.4)$ & $3.1(2.1)$ & 4.27 & 0.001 \\
\hline Pliability & $6.21(2.4)$ & $3.03(1.5)$ & 4.9 & 0.001 \\
\hline Pigmentation & $6.44(2.6)$ & $3.7(2.7)$ & 8.6 & 0.001 \\
\hline Relief & $5.6(2.4)$ & $3.5(2.3)$ & 4.30 & 0.001 \\
\hline $\begin{array}{l}\text { Total observer } \\
\text { score }\end{array}$ & 31 (8.5) & $18(6.8)$ & 11.41 & 0.001 \\
\hline
\end{tabular}

Table 4: Association between aesthetic outcome and duration of scar

\begin{tabular}{lcccc}
\hline $\begin{array}{l}\text { Duration } \\
\text { of scar }\end{array}$ & \multicolumn{2}{c}{ Outcome } & Total (\%) & $\begin{array}{r}\text { Fischer exact } \\
\text { test } \boldsymbol{P}^{*}\end{array}$ \\
\cline { 2 - 3 } Good $^{* *}(\%)$ & Bad $^{\sharp}(\%)$ & & 0.001 \\
\hline$<5$ years & $25(92.6)$ & $2(7.4)$ & $27(100)$ & \\
$>5$ years & $1(14.3)$ & $6(85.7)$ & $7(100)$ & \\
Total & 26 & 8 & 34 & \\
\hline${ }^{*} P<0.05$ significant, ${ }^{* *}$ POSAS total score: $6-24$, " POSAS total score: $25-60$.
\end{tabular}

POSAS: Patient and Observer Scar Assessment Scale 
injection. There was a significant improvement in the scar as shown in Figure 5a (pre-operative) and Figure 5b (post-operative). The total POSAS score also showed improvement.

\section{Case 3}

A 42-year-old female with post-traumatic irregular scar on the forehead of 18 months duration underwent emulsified fat injection. There was a significant improvement as shown in Figure 6a (pre-operative) and Figure 6b (post-operative).

\section{Case 4}

A 39-year-old female with post-traumatic scar dorsum of the nose of 1 year duration. She underwent emulsified fat injection on the scar. Pre-operative [Figure 7a] and post-operative photographs [Figure $7 \mathrm{~b}$ ] and the POSAS scores showed significant improvement.

\section{DISCUSSION}

Autologous structural fat grafting has been used for over a century in various contour correction and aesthetic procedures..$^{[4,5]}$ Zuk et al. ${ }^{[6]}$ in 2001, introduced ADSC which are multipotent, undifferentiated, self-renewing progenitor cells resembling mesenchymal stem cells..$^{[6,7]}$ These adipose-derived stem cells have emerged as a key

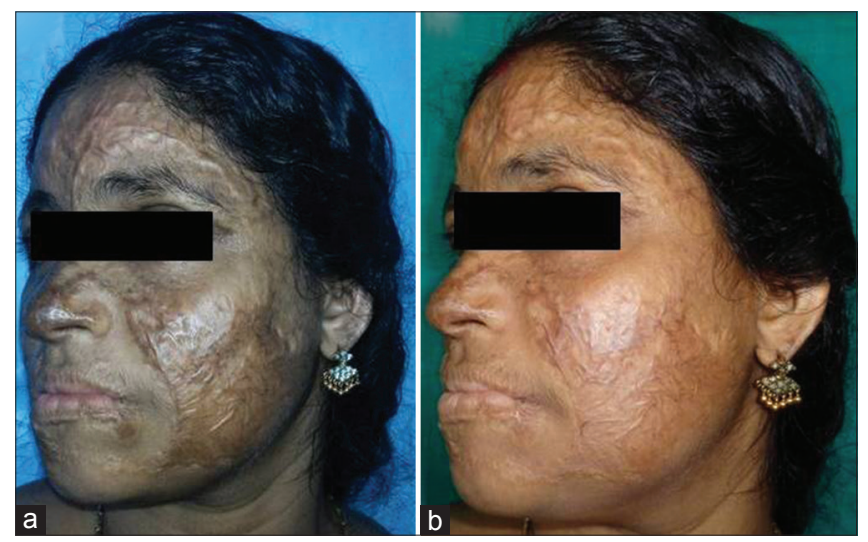

Figure 4: Pre-operative (a) and post-operative (b) photographs after injection of autologous emulsified fat in post-burns facial scar
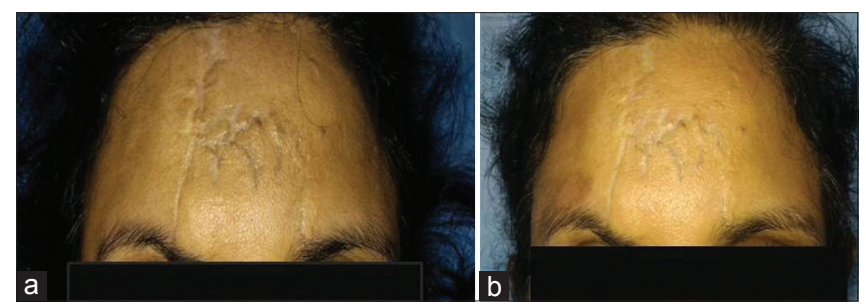

Figure 6: Pre-operative (a) and post-operative (b) photographs after injection of autologous emulsified fat in post-traumatic scar element in regenerative medicine due to their ability to differentiate into a variety of different cell lineages and their anti-apoptotic, anti-inflammatory, proangiogenic, immunomodulatory and anti-scarring properties. ${ }^{[8]}$ The lipoaspirate harvested by liposuction contains adipocytes and a heterogeneous stromal vascular fraction which include fibroblasts, endothelial cells, pre-adipocytes, vascular smooth muscles, lymphocytes, monocytes and ADSCs. ${ }^{[8]}$ The study of Tonnard et al..$^{[1]}$ in 2013, on nanofat grafting has shown that even though emulsified fat or nanofat is devoid of viable adipocytes, the number of ADSCs with regenerative potential is retained in the nanofat sample. The study evaluated the efficacy of nanofat injection in the improvement of scar regarding patient symptoms such as pain, itching, colour, stiffness and thickness and qualitative scar characteristics such as vascularity, pigmentation, thickness and pliability using a standardised, validated tool POSAS and also with photographs. This study is unique in that the assessment of scar improvement with nanofat injection using a standard tool has not been reported in the literature. The study has proven that nanofat injection improves the aesthetic appearance as well as the quality and texture of the scar and hence can be used in patients with disfiguring scars.

The technique of nanofat injection is cost-effective when compared to other commonly used conservative modalities of treatment of scars such as silicone gel or sheet application and compression garment therapy ${ }^{[9]}$ Moreover, silicone gel/gel sheet application

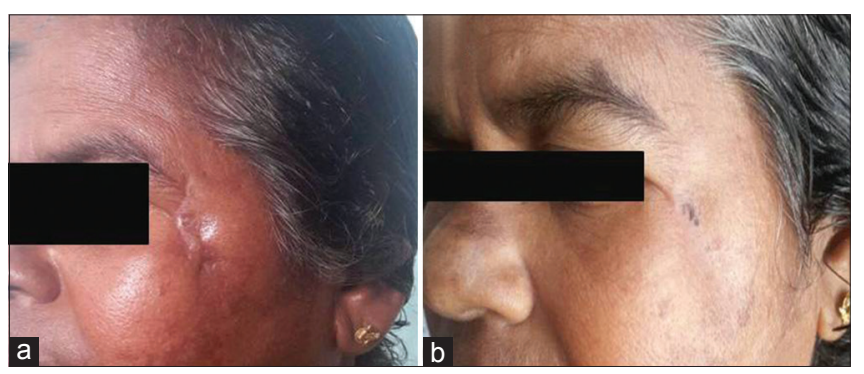

Figure 5: Pre-operative (a) and post-operative (b) photographs after injection of autologous emulsified fat in post-traumatic scar

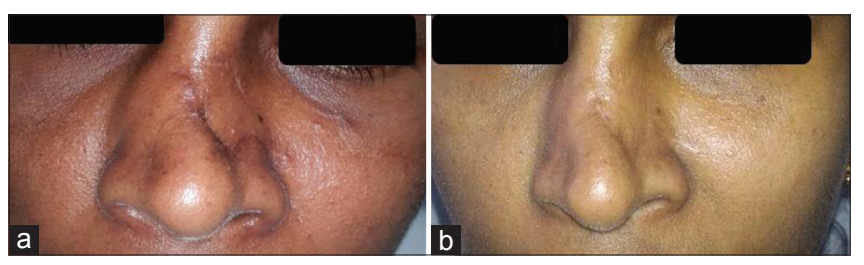

Figure 7: Pre-operative (a) and post-operative (b) photographs after injection of autologous emulsified fat in post-traumatic scar dorsum of nose 
and compression therapy require application for a long duration to obtain desirable effects and hence require proper counselling and patient compliance for the success of the treatment. ${ }^{[9]}$ Nanofat injection, on the other hand, does not need post-operative scar care therapies for the results as the effect of scar improvement is due to the rejuvenating property of the ADSCs.

Corticosteroid injection given for hypertrophic scarring has many disadvantages such as severe pain on injection, local skin and subcutaneous tissue atrophy and hypopigmentation. ${ }^{[10]}$ In addition, systemic complications like deranged blood glucose levels make it unsuitable for diabetics. In contrast to a steroid injection, nanofat injection has no systemic complication as the injected fat is autologous. Local swelling due to fat injection will disappear in about 2-3 weeks' time as all the emulsified fat will be absorbed while scar will improve progressively.

Other modalities of treatment such as laser, chemical peel and dermabrasion cause tissue destruction and reepithelisation. ${ }^{[11-13]}$ In nanofat injection, there is no destruction of the tissue, but the scar improves as a result of the regenerative property of stem cells.

Alloplastic dermal fillers may cause immunogenic reactions as well as hypersensitivity. ${ }^{[12]}$ Nanofat injection is safer as this is autologous.

Surgical scar revision creates another scar which may or may not give good results with added physical, psychological and financial burden to the patient. ${ }^{[14]}$ Nanofat injection improves the existing scar by its rejuvenating property and hence will be more acceptable to the patient. The technique of nanofat harvesting, processing and injection is simple and can be easily mastered by a cosmetic surgeon. The procedure can be done under local anaesthesia and hence does not require a hospital stay making this a day care procedure. As liposuction is done with a $3 \mathrm{~mm}$ cannula and fat injection with $27 \mathrm{G}$ needle and insulin syringe, the procedure is sutureless. This avoids the need for suture removal and makes the procedure more acceptable to the patient. The rejuvenating property of nanofat is of prime importance in extensive facial scarring as in burns where no other surgical procedure like skin grafting or flap surgery can improve the aesthetic appearance of the already scarred and disfigured face. This gives the patient much psychological satisfaction, reduces the financial burden of costly surgeries.
The study is unique in that, patient's opinion regarding the scar is also scored and compared with the post-operative results thereby reducing the observer bias in the result. In this study, it was noted that atrophic hyperpigmented long duration scars showed less improvement with nanofat injection. Two patients with such scars were not satisfied with the results after fat injection and demanded scar revision. They underwent scar revision, and nanofat injection was given on the post-operative scar after 6 weeks, and the results were satisfactory. Nanofat grafting can be given in a scar irrespective of aetiology. However, fat injection done in two burns scars with keloid tendency has shown some symptomatic worsening of itching, redness and excoriation of the scar following injection when required intralesional steroid injection for relieving the symptoms. The study was conducted in a single tertiary care centre and hence multicentric randomised control trials are required for validation of results in large samples. The effect of nanofat injection on scars of varying aetiologies has to be studied separately on a larger sample size.

\section{CONCLUSION}

Autologous emulsified nanofat injection is an easily mastered, day-care surgical procedure for scar rejuvenation with minimal complications and good patient compliance. It improves the symptoms as well as the texture of all types of scars, particularly of short duration. Nanofat grafting is a promising modality in patients with extensive facial burns scarring where alternative treatment options are limited.

\section{Declaration of patient consent}

The authors certify that they have obtained all appropriate patient consent forms. In the form, the patients have given their consent for their images and other clinical information to be reported in the journal. The patients understand that their names and initials will not be published and due efforts will be made to conceal their identity, but anonymity cannot be guaranteed.

\section{Acknowledgment}

I specially thank my colleagues and residents, Plastic Surgery Department, Medical College, Kottayam for providing support and help in preparing manuscript. I also thank my patients who had participated in this study.

\section{Financial support and sponsorship}

Nil. 


\section{Conflicts of interest}

There are no conflicts of interest.

\section{REFERENCES}

1. Tonnard P, Verpaele A, Peeters G, Hamdi M, Cornelissen M, Declercq $\mathrm{H}$, et al. Nanofat grafting: Basic research and clinical applications. Plast Reconstr Surg 2013;132:1017-26.

2. Draaijers LJ, Tempelman FR, Botman YA, Tuinebreijer WE, Middelkoop E, Kreis RW, et al. The patient and observer scar assessment scale: A reliable and feasible tool for scar evaluation. Plast Reconstr Surg 2004;113:1960-5.

3. van de Kar AL, Corion LU, Smeulders MJ, Draaijers LJ, van der Horst CM, van Zuijlen PP, et al. Reliable and feasible evaluation of linear scars by the patient and observer scar assessment scale. Plast Reconstr Surg 2005;116:514-22.

4. Coleman SR. Structural fat grafts: The ideal filler? Clin Plast Surg 2001;28:111-9.

5. Marwah M, Kulkarni A, Godse K, Abhyankar S, Patil S, Nadkarni $\mathrm{N}$, et al. Fat ful'fill'ment: A review of autologous fat grafting. J Cutan Aesthet Surg 2013;6:132-8.
6. Zuk PA, Zhu M, Mizuno H, Huang J, Futrell JW, Katz AJ, et al. Multilineage cells from human adipose tissue: Implications for cell-based therapies. Tissue Eng 2001;7:211-28.

7. Deans RJ, Moseley AB. Mesenchymal stem cells: Biology and potential clinical uses. Exp Hematol 2000;28:875-84.

8. Frese L, Dijkman PE, Hoerstrup SP. Adipose tissue-derived stem cells in regenerative medicine. Transfus Med Hemother 2016;43:268-74.

9. Stavrou D, Weissman O, Winkler E, Yankelson L, Millet E, Mushin OP, et al. Silicone-based scar therapy: A review of the literature. Aesthetic Plast Surg 2010;34:646-51.

10. Roques $C$, Téot $L$. The use of corticosteroids to treat keloids: A review. Int J Low Extrem Wounds 2008;7:137-45.

11. Ogawa R. The most current algorithms for the treatment and prevention of hypertrophic scars and keloids. Plast Reconstr Surg 2010;125:557-68.

12. Gozali MV, Zhou B. Effective treatments of atrophic acne scars. J Clin Aesthet Dermatol 2015;8:33-40.

13. Cooper JS, Lee BT. Treatment of facial scarring: Lasers, filler, and nonoperative techniques. Facial Plast Surg 2009;25:311-5.

14. Garg S, Dahiya N, Gupta S. Surgical scar revision: An overview. J Cutan Aesthet Surg 2014;7:3-13. 